\title{
Three dimensional modelling of beta endorphin and its interaction with three opioid receptors
}

\author{
Swathi Aluri* and Ramana Terli \\ Department of Biotechnology, College of Science and Technology, Andhra University, Visakhapatnam - 530003, \\ Andhra Pradesh, India. \\ Accepted 31 May, 2012

\begin{abstract}
Beta endorphin is a neurotransmitter and is involved in functions like enhancement of immune system, deceleration of cancer cell growth and induction of euphoria and relaxation. It is an opioid like neuropeptide synthesized in neurons of hypothalamus and pituitary gland. The study of its structure and its interaction with opioid receptors can throw light on its neuropsychopharmacology. Protein data bank does not contain the structural information of beta endorphin and mu opioid receptor. Hence, in the present study, we aimed at predicting their three dimensional structures. Owing to homologues with low sequence identity and unsatisfactory results from threading methods, we resorted to $a b$ initio modelling. Quark algorithm was used for beta endorphin structure prediction. The structure of mu opioid receptor was modelled by I TASSER simulations. The quality of the protein models were evaluated with PROCHECK server. Functionally important regions in beta endorphin were located using ConSurf web server. Docking studies were performed on beta endorphin with three opioid receptors $\mathrm{mu}$, kappa and gamma to anticipate residues important for binding.
\end{abstract}

Key words: $A b$ initio modelling, homology, docking, beta endorphin, opioid receptors, threading, QUARK, PROCHECK, AUTODOCK, template, binding sites.

\section{INTRODUCTION}

Beta endorphin was discovered by Li and Chung (1976) from camel pituitary glands. In Homo sapiens, it comprises of 31 amino acids. It is processed from 267 amino acids long proopiomelanocortin protein. Beta endorphin synthesized in pituitary gland is released into blood and that synthesized in hypothalamus is transuded

*Corresponding author. E-mail: swathialuri@yahoo.com. Tel: + 919000456568.

Abbreviations: ACTH, Adrenocorticotropic hormone; CASP, critical assessment of techniques for protein structure prediction; GRAMM, global range molecular matching; JCSG, joint centre for structural genomics; NCBI, National Centre for Biotechnology Information; PDB, protein data bank; PSI Blast, position specific iterated blast; RMS, root mean square distance. into spinal cord and brain. Owing to blood brain barrier, beta endorphin released into blood cannot enter brain in sizeable quantities. It is produced in vertebrates during excitement, pain, orgasm and exercise. Beta endorphin stimulates the release of growth hormone, ACTH, prolactin and antidiuretic hormone and inhibits the release of thyrotropin, luteinizing hormone and follicle stimulating hormone (Chrétien et al., 1981). Major function of beta endorphin, however, is regulation of pain. Pain receptors in the skin sense the pain and send the pain impulse to the thalamus via spinal cord and then to sensory and motor cortices. The pain receptors broadcast pain by releasing a transmitter called substance $P$. Substance $P$ is a neurotransmitter found in neurons at both sides of dorsal horns of spinal cord. It causes other neurons to fire in response to pain impulse. The dorsal horns also contain endorphin containing neurons. Endorphins are released from these neurons 
synapse between two pain transmitting neurons and inhibit the release of substance $P$ thereby sending fewer pain impulses to brain (Dalayeun et al., 1993).

Its function is mediated by its interaction with opioid receptors. There are three subtypes of opioid receptors mu, gamma and kappa. Naloxone is a competitive antagonist to mu opioid receptor. Beta endorphin has highest affinity for mu 1 opioid receptor and least affinity for kappa 1 opioid receptor. The order of its affinity for opioid receptors is: mu $1>$ mu $2>$ delta $>$ kappa 1 . Docking studies were performed on beta endorphin with three opioid receptors mu, kappa and gamma to anticipate residues important for binding (Janecka et al., 2004).

\section{METHODOLOGY}

The protein sequences of beta endorphin and mu opioid receptor were obtained from protein knowledgebase (UniprotKB) (Bairoch et al., 2004). The NCBI Blast (Altschul et al., 1990) server was used to find structural templates for beta endorphin and mu opioid receptor. PSI Blast was carried out against Protein Data Bank (PDB) (Bernstein et al., 1977). Suitable templates could not be found for modelling beta endorphin and mu opioid receptor. Protein threading methods did not provide reliable results as well. Hence, we resorted to $a b$ initio modelling.

QUARK

algorithm

(http://zhanglab.ccmb.med.umich.edu/QUARK/) was used to predict the three dimensional structures of beta endorphin. I -Tasser simulations (Ambrish et al., 2010) deduced the structure of mu opioid receptor. I - Tasser and QUARK servers were ranked number 1 and number 2 respectively in CASP 9 experiments. Models predicted using QUARK algorithm and I - Tasser simulations were submitted to JCSG server for structure validation. Evaluation reports were generated from PROCHECK (Laskowski et al., 1993). It performs assessment of various parameters of the models such as bond length, bond angle, residue by residue properties, main chain properties, side chain properties, RMS distance from planarity and distorted geometry plots (Morris et al., 1992). ConSurf web server was used to predict functionally important regions of beta endorphin (Glaser et al., 2003). This automated web server calculates the degree of conservation of amino acids among close sequence homologues of the query protein. These conservation patches are envisaged onto the molecular surface of proteins to expose the patches of highly conserved residues. Highly conserved residues are often crucial for biological functions.

The structures of the other two opioid receptors - kappa and delta were obtained from PDB (Protein Data Bank). The molecular interaction studies of beta endorphin with three opioid receptors were performed using AutoDock tools. AutoDock software consists of two programs - autodock and autogrid. Autodock program docks ligand molecule onto a set of grids outlining the target molecule or protein. These grids are calculated by autogrid program (Morris et al., 1998).

\section{RESULTS AND DISCUSSION}

\section{Beta endorphin modelling}

\section{Sequence analysis}

The protein sequence of beta endorphin was obtained from protein knowledgebase (UniprotKB) (Homo sapiens beta endorphin protein sequence (Length - 31 amino acids)).

\section{YGGFMTSEKSQTPLVTLFKNAIIKNAYKKGE}

Proopiomelanocortin protein in Homo sapiens (POMC ID - P01189) is cleaved at $237^{\text {th }}$ residue to yield beta endorphin.

\section{Ab initio modelling}

$A b$ initio protein structure prediction method is based on thermodynamic hypothesis which states that for native structure of protein the free energy achieves the global minimum. Hence, in this method, all the energetics involved in protein folding is modelled and the structure with lowest free energy is found. Though it is computationally intensive, it is a very good approach for protein modelling.

We used QUARK algorithm for beta endorphin structure prediction. In this method, models are built under the focal point of atomic level knowledge based force field. Replica Exchange Monte Carlo simulation is used to build protein models from small fragments. In Critical Assessment of Structure Prediction (CASP) 9 experiment, QUARK is ranked number 1 in Free Modelling section. Ten models were predicted by QUARK server. The most accurate model was model (a) (Figure 1)

\section{Structure validation}

Verification and evaluation was performed by PROCHECK server. $96 \%$ of the residues were in favourable region of Ramachandran plot and other parameters in PROCHECK were also in allowed ranges. Hence, the quality of the predicted model is good (Figure 2).

\section{Analysis of important residues in beta endorphin theoretical model}

ConSurf server predicted high conservation scores for residues tyr1, gly3, phe4, met5, pro13, leu14, thr16, leu17, phe18, asn20, ala21, ile 22, lys24, lys28, lys29. High scores assigned to these residues are indicative of evolutionary conservation and their functional significance (Figure 3).

\section{Mu opioid receptor modelling}

\section{Sequence analysis}

The UniprotKB entry for human mu opioid receptor 


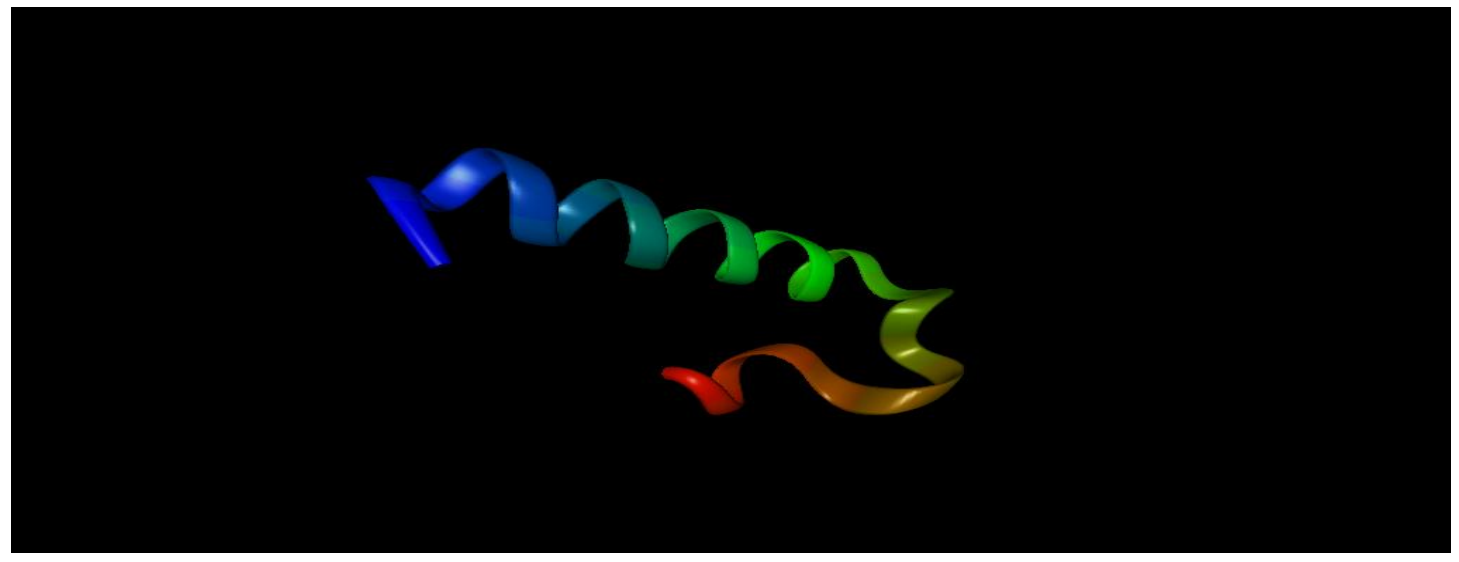

Figure 1. Theoretical model of beta endorphin. Ab initio modelling was performed by QUARK. The images were generated using PYMOL (http://www.pymol.org).

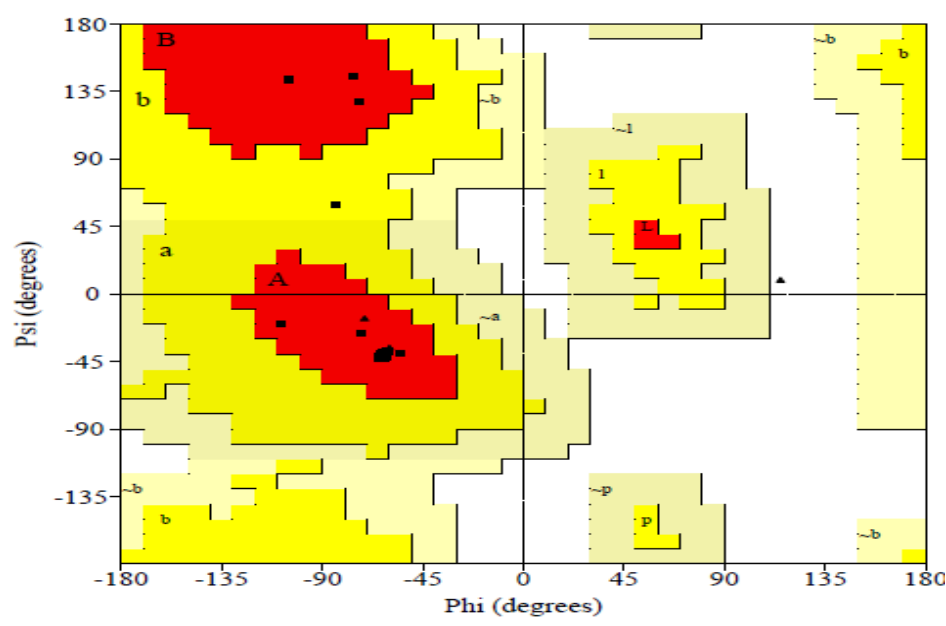

Figure 2. Ramachandran plot for theoretical model of beta endorphin.
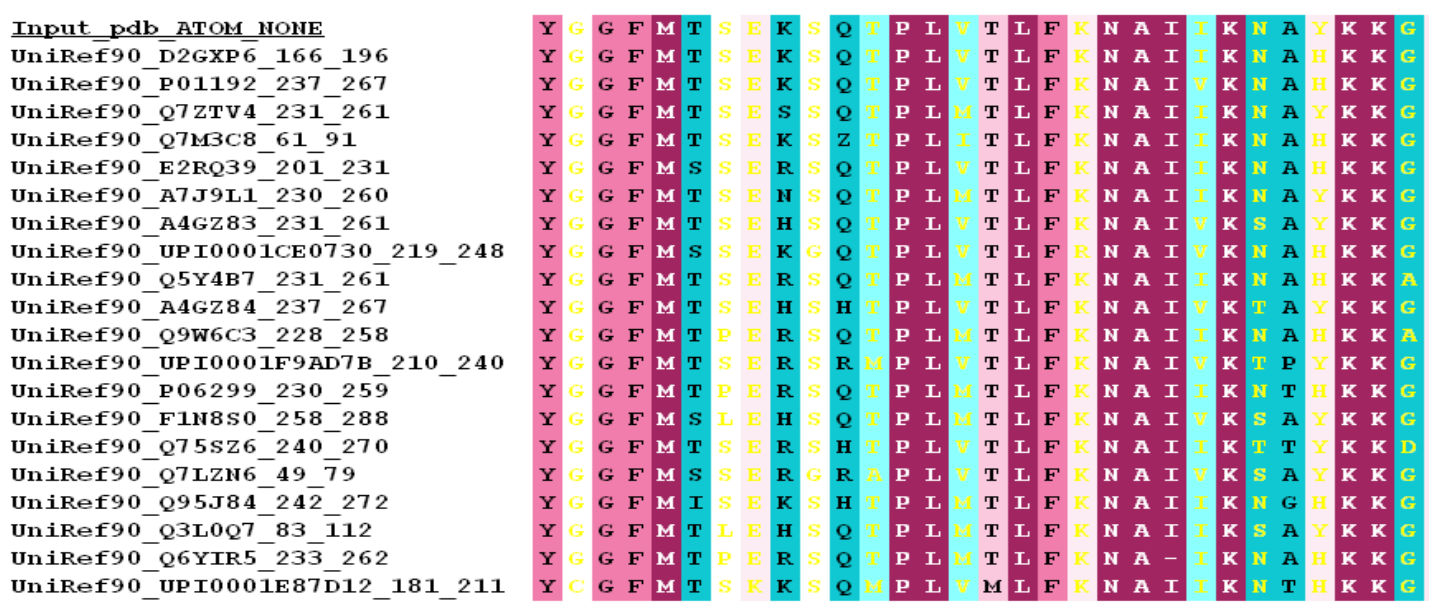

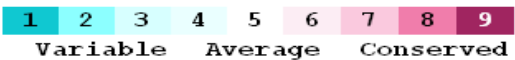

Figure 3. ConSurf analysis: The amino acids of beta endorphin are coloured in range from turquoise to maroon based on conservation grades. 


\begin{abstract}
$>s p|P 35372|$ OPRM_HUMAN Mu-type opioid receptor OS=Homo sapiens GN=OPRM1 PE=1 SV=2 MDSS ÅAPTNASNCTD $\overline{\text { ALL }}$ AYSSCSP APSPGSWNNLSHLDGNLSDPCGPNRTDLGGRDSLCP PTGSPSMITAITIMAL YS IVCVVGLF GNF LVMYVIVRYTKMKTATN I Y IFNL AL ALD ALA AT STLPF QSVNYL MGTWPF GT ILCKIV IS ID YYNMF TS IF TLCTMSVDRY I AVCHPVKALDF RTPRNAKI INVCNW ILSS A I GL PVMF MA TTKYRQGS IDCTL TF SHP TWYWENLLKICVF I FAF IMPVL I I TVCYGL MILRL KSVRMLSGSKE KDRNLRR I TRMVLWVAVF IVCUTP IHI YVI IKALVT IPETTFQTVSWHFCI ILLGYTNSCLNPVL YAF LDENF KRCF REFC IPTSSN I EQQNSTR IRQNTRD HPST MANTVDRTNHQLENLE ÄETÄPLP
\end{abstract}

Figure 4. Homo sapiens mu opioid receptor sequence.

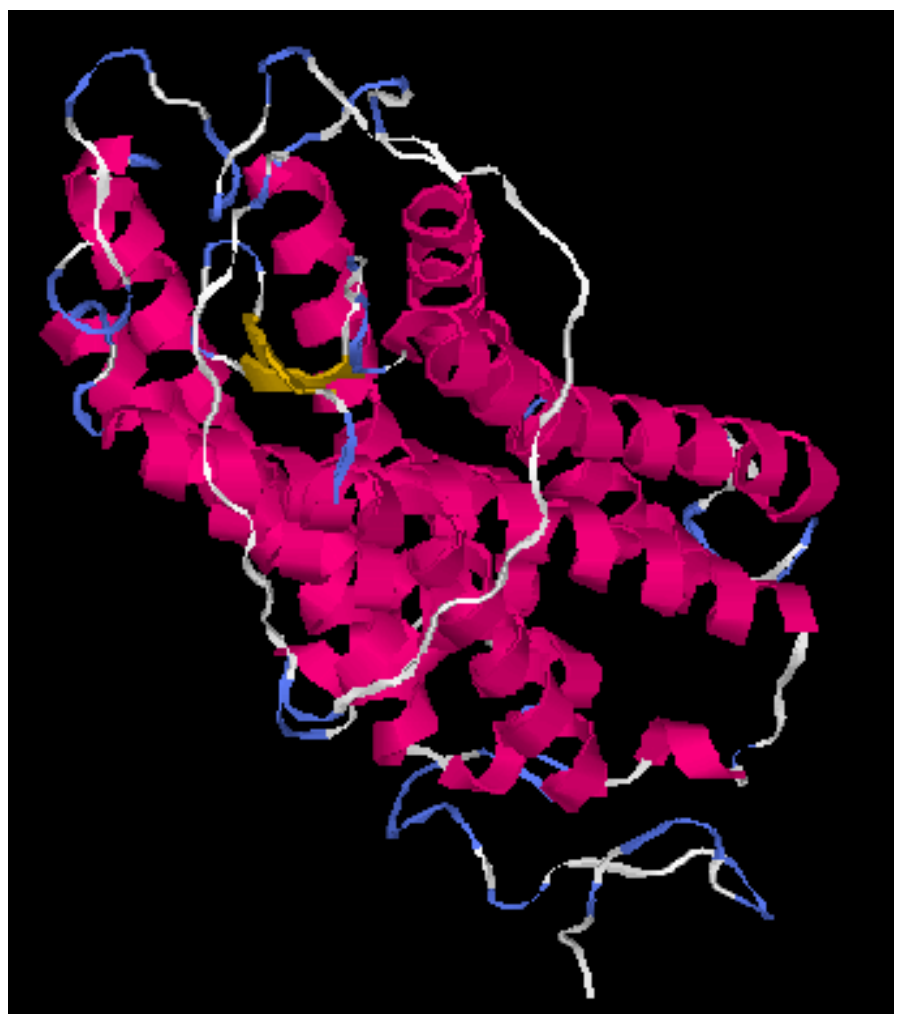

Figure 5. Theoretical model of mu opioid receptor. Modelling was performed by I TASSER.

(P35372) is used for modelling. The protein is Homo sapiens in origin and is 400 amino acids long (Figure 4).

\section{Ab initio modelling}

We used I-TASSER server for modelling mu opioid receptor structure. The server generates the structure from a query protein sequence in three steps. In the first step, it tries to find possible templates for the query protein using LOMETS (Local Meta Threading Server). The fragments expunged from different PDB templates are assembled into full length models by replica exchange Monte Carlo simulations in the second step. Gaps created by unaligned regions are built by $a b$ initio modelling. The low free energy state models are determined by an algorithm, SPICKER, through gathering simulation decoys. In the third step, SPICKER cluster steroids are used as starting material for performing fragment assembly simulation. This simulation is performed to remove steric clashes and improve the global topology of cluster centroids. The lowest energy structures are selected from clustered decoys obtained from second simulation. The final atomic models are built from these selected structures using REMO which optimizes hydrogen bonding network. Five energy minimized models resulted from I TASSER simulations and first model was found to be the best (Figure 5).

\section{Structure validation}

PROCHECK analysis showed that only 4 out of 400 residues of mu opioid receptor were in disallowed region. $2.2 \%$ of the residues were in generously allowed region, $38 \%$ of the residues were in additionally allowed regions and $86.1 \%$ of the residues were in most favoured regions. Hence the quality of the predicted model is considered satisfactory (Figure 6).

\section{Docking studies: Interaction of beta endorphin with three opioid receptors}

We report first study of interaction of beta endorphin with three opioid receptors. Earlier, interaction of opioid receptors with ligands JOM6, JOM13 and MP16, respectively, were studied by Irina $D$ Pogozheva et al. (2005). The docking studies of beta endorphin with three opioid receptors were performed to determine the important beta endorphin residues involved in interaction. Docking studies were performed with AutoDock tools. Structures of beta endorphin and mu opioid receptor were modelled in the present study. The structures of the other two opioid receptors were obtained from PDB (Protein Data Bank). Hydrogen bonds and hydrophobic interactions between beta endorphin and opioid receptors were studied using LigPlot (Wallace et al., 1995). The docking studies showed that the residues Tyr 1, Gly 2, Gly 3, Gln 11, Thr 12, Pro 13, Leu 14, and Val 15 of beta endorphin interacted with mu opioid receptor (Figure 7). Lys 9, Gln 11, Thr 12, Pro 13, Leu 14, Val 15, Phe 18, 


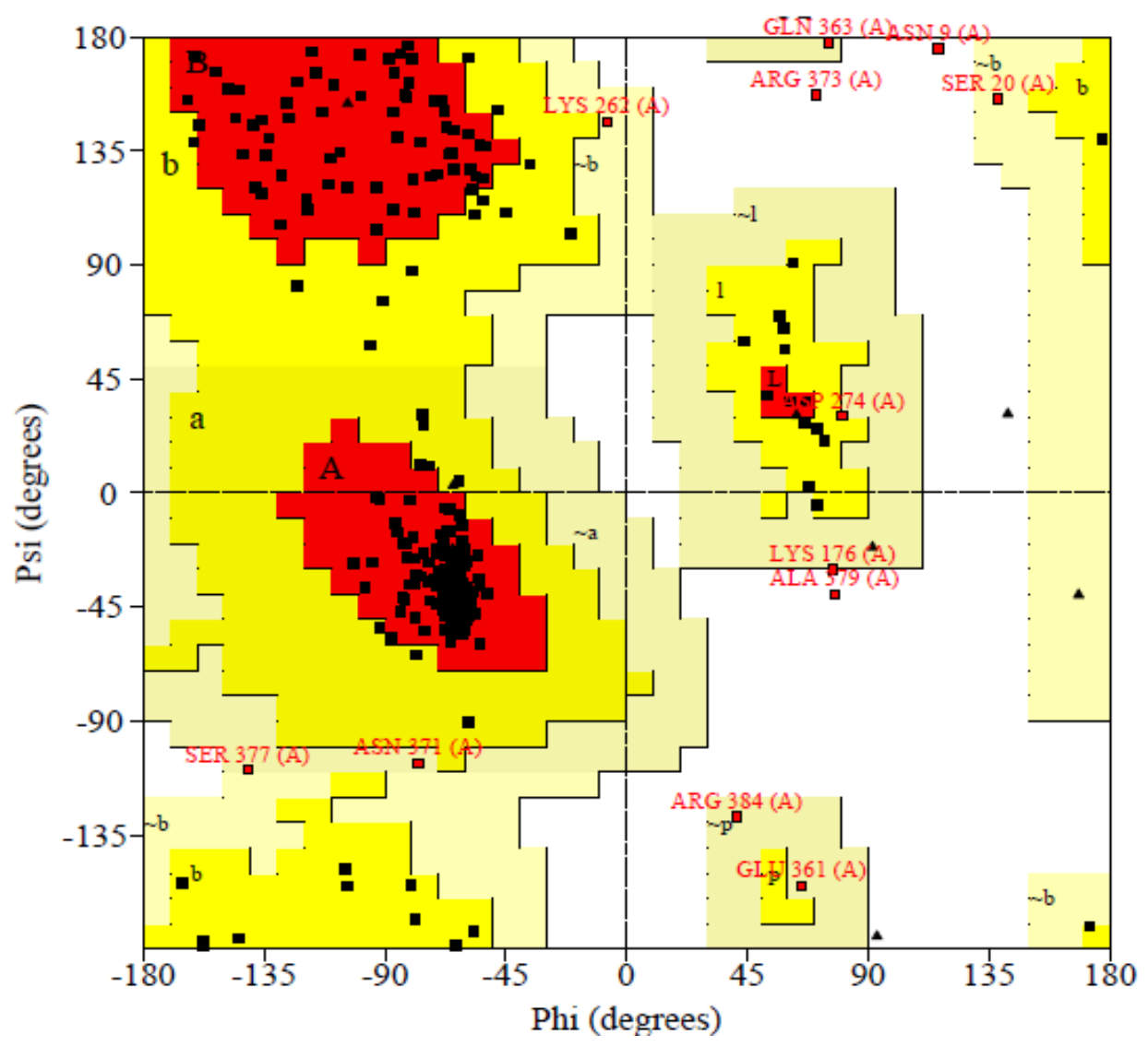

Figure 6. Ramachandran plot for theoretical model of mu opioid receptor.

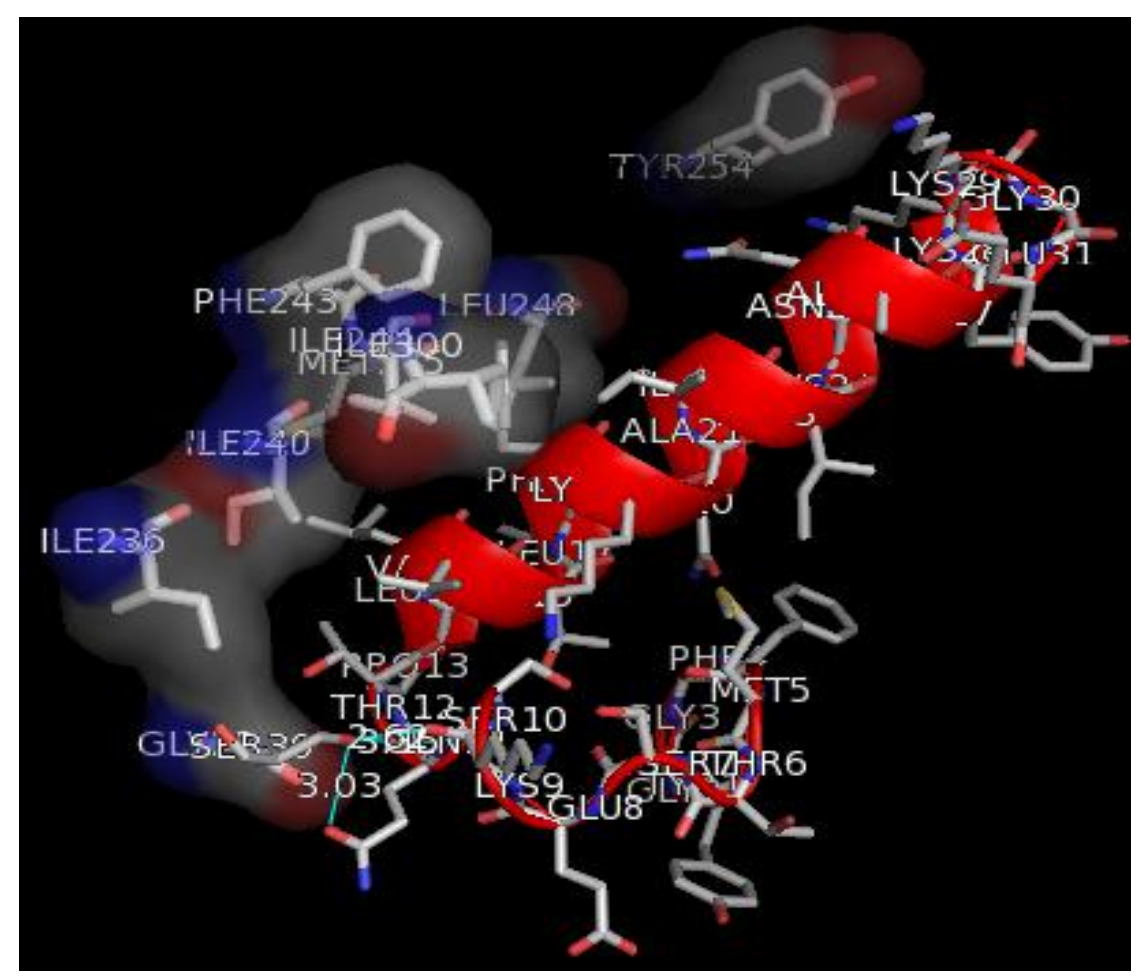

Figure 7. Interaction between beta endorphin and mu opioid receptor after docking. 


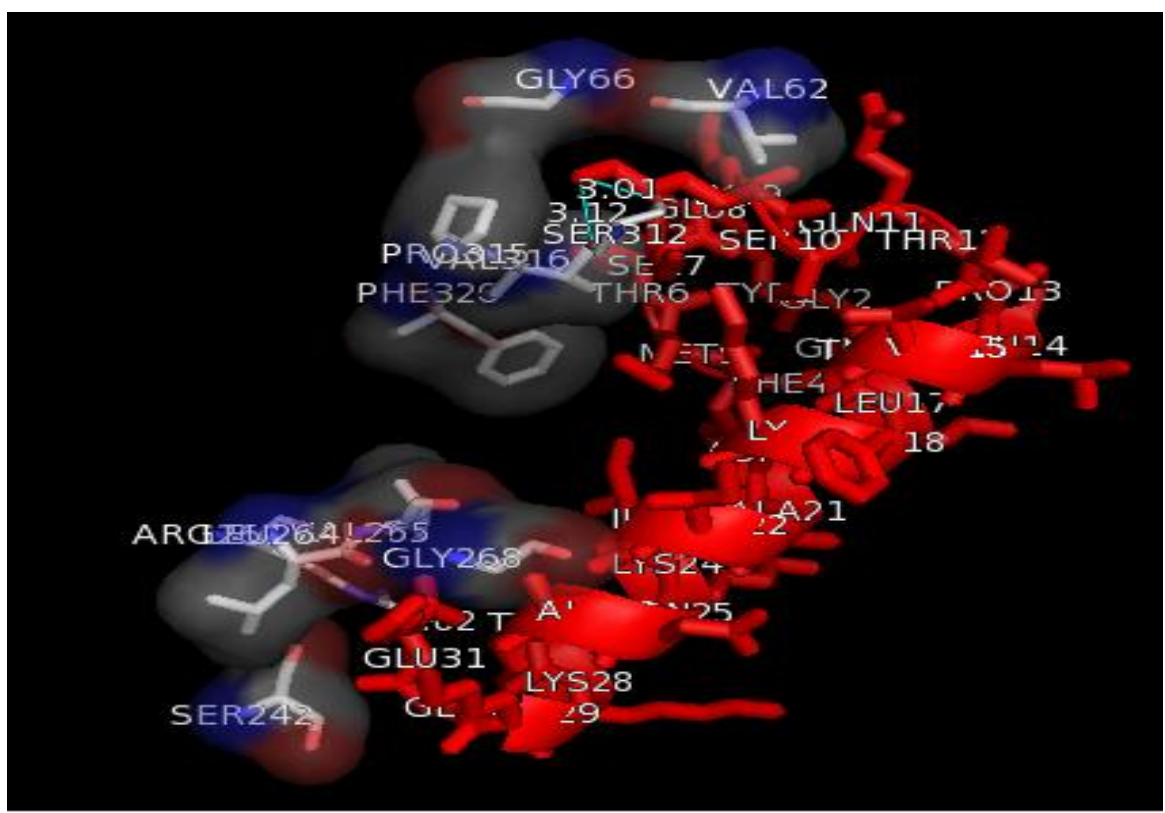

Figure 8. Interaction between beta endorphin and delta opioid receptor after docking.

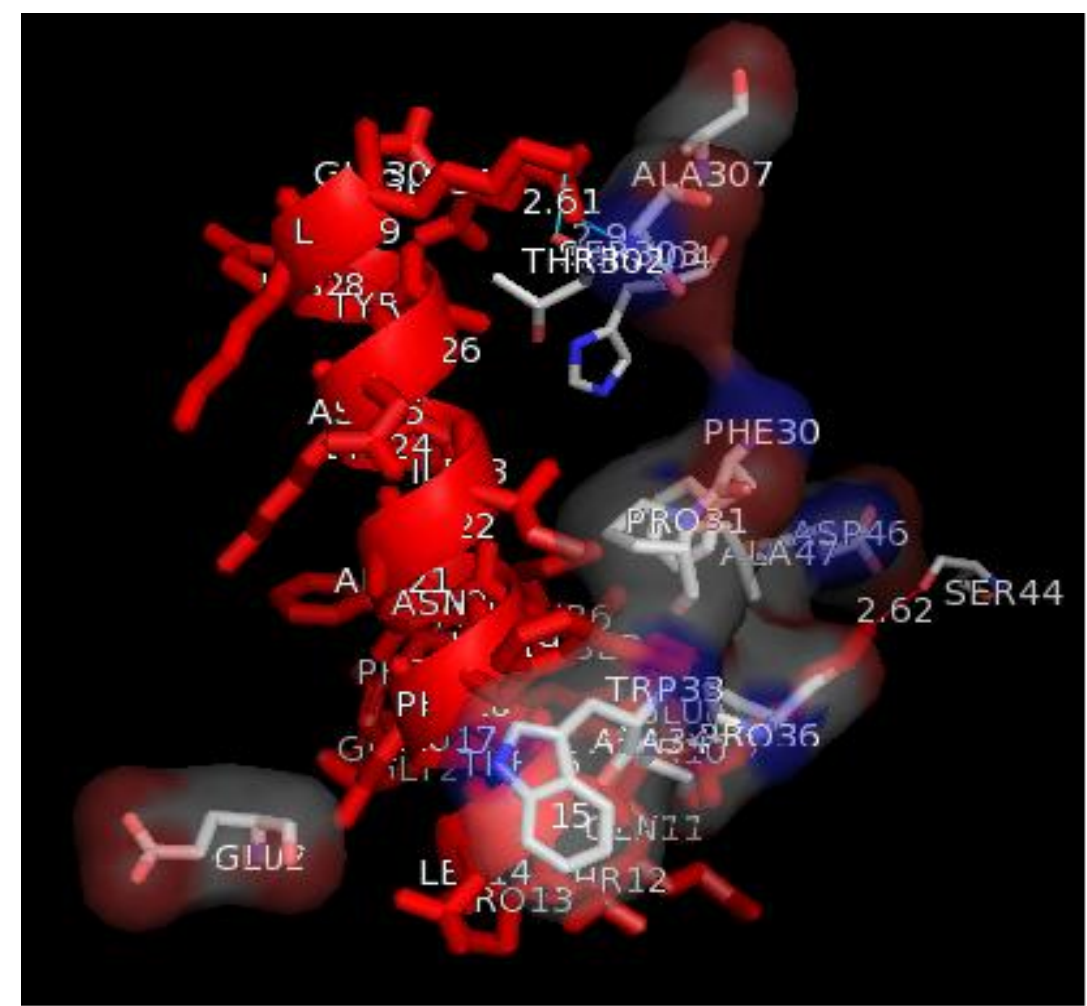

Figure 9. Interaction between beta endorphin and kappa opioid receptor after docking.

Lys 19 and Lys 29 residues of beta endorphin were found to be important for its binding to delta opioid receptor (Figure 8). With kappa opioid receptor, Tyr 1, Gly 2, Gly
3, Phe 4, Thr 6, Lys 9, Phe 18, lle 22, Ala 26, Tyr 27, Lys 29 and Glu 31 residues of beta endorphin were involved in interaction (Figure 9). ConSurf server predicted 
Table 1. The amino acid residues involved in interaction between beta endorphin and three opioid receptor types.

\begin{tabular}{ll}
\hline Complex & Residues of beta endorphin involved in interaction \\
\hline Beta endorphin and mu opioid receptor & Tyr 1, Gly 2, Gly 3, Gln 11, Thr 12, Pro 13, Leu 14, Val 15 \\
Beta endorphin and delta opioid receptor & Lys 9, Gln 11, Thr 12, Pro 13, Leu 14, Val 15, Phe 18, Lys 19, Lys 29 \\
Beta endorphin and kappa opioid receptor & Tyr 1, Gly 2, Gly 3, Phe 4, Thr 6, Lys 9, Phe 18, Ile 22, Ala 26, Tyr 27, Lys 29, Glu 31 \\
\hline
\end{tabular}

Table 2. The amino acid residues involved in interaction between beta endorphin and three opioid receptor types.

\begin{tabular}{ll}
\hline Complex & Residues of opioid receptor involved in interaction \\
\hline \multirow{2}{*}{ Beta endorphin and mu opioid receptor } & $\begin{array}{l}\text { Thr 69, Leu 76, Pro 297, Tyr 301, Thr 313, Ser 319, His 321, Phe 322, Cys 323, Ala } \\
\text { 325, Leu 326 }\end{array}$ \\
Beta endorphin and delta opioid receptor & $\begin{array}{l}\text { Leu 55, Tyr 56, Val 59, Val 62, Arg 244, Leu 245, Ser 247, Val 265, Val 272, Leu } \\
\text { 306, Ala 309, Ser 312, Leu 313, Val 316 }\end{array}$ \\
& Glu 2, Ser 3, Pro 4, Ile 5, Gln 6, Glu 35, Pro 36, Ser 44, Asp 46, Ala 47, Glu 50, Thr \\
Beta endorphin and kappa opioid receptor & 302, Ser 303, His 304 \\
\hline
\end{tabular}

residues Tyr1, Gly3, Phe4, Met5, Pro13, Leu14, Thr16, Leu17, Phe18, Asn20, Ala21, Ile 22, Lys24, Lys28, and Lys29 to be evolutionarily conserved (Tables 1 and 2). ConSurf results are found to be in concurrence with the results of docking studies performed between beta endorphin and three opioid receptors. Gln 11 residue of beta endorphin was involved in interaction with mu opioid receptor and delta opioid receptor. Lys 9 , Phe 18 and Lys 29 residues of beta endorphin were found to be involved in binding with both delta and kappa opioid receptor. ConSurf predicted high conservation scores for Gln 11, Lys 9, Phe 18 and Lys 29 residues of beta endorphin.

\section{Conclusion}

Our work on ab initio modelling of beta endorphin and mu opioid receptor was helpful in inferring the binding pattern of these proteins. The docking results and ConSurf analysis results were in agreement with each other manifesting the pivotal residues. Thus, the present work provides valuable insight for future studies into the role of beta endorphin in biological processes.

\section{ACKNOWLEDGEMENT}

The authors acknowledge the facilities provided by the Department of Biotechnology, Andhra University, Visakhapatnam, 530003, India.

\section{REFERENCES}

Altschul SF, Gish W, Miller W, Myers EW, Lipman DJ (1990). Basic local alignment search tool. J. Mol. Biol. 215:403 [PMID:2231712].
Ambrish R, Alper K, Yang (2010). I-TASSER: a unified platform for automated protein structure and function prediction. Nature Protoc. 5:725-738 PMID:20360767.

Bairoch A, Boeckmann B, Ferro S, Gasteiger E (2004). Swiss Prot: juggling between evolution and stability. Brief Bioinform. 5:39 [PMID: 15153305].

Bernstein FC, Koetzle TF, Williams GJ, Meyer EE Jr, Brice MD, Rodgers JR, Kennard O, Shimanouchi T, Tasumi M (1977). The Protein Data Bank: A Computer-based Archival File For Macromolecular Structures J. Mol. Biol. 112:535. http://zhanglab.ccmb.med.umich.edu/QUARK/

Chrétien M, Seidah NG, Scherrer H (1981). Endorphins: Structure, roles and biogenesis. Can. J. Physiol. Pharmacol. 59(5):413-431. PMID:6263434.

Dalayeun JF, Norès JM, Bergal S (1993). Physiology of beta endorphins. A close up view and a review of the literature. Biomed. Pharmacother. 47(8):311-320. PMID: 7520295.

Glaser F, Pupko T, Paz I, Bell RE, Bechor D, Martz E, Ben-Tal N (2003). ConSurf: identification of functional regions in proteins by surface-mapping of phylogenetic information. Bioinformatics 19:163 [PMID:12499312]

Janecka A, Fichna J, Janecki T (2004). Opioid receptors and their ligands. Curr. Top. Med. Chem. 4(1):1-17. PMID:14754373.

Laskowski RA; MacArthur MW; Moss DS; Thornton JM (1993). PROCHECK: a program to check the stereochemical quality of protein structures. J. Appl. Cryst. 26:283 [doi:10.1107/S0021889892009944].

Li CH, Chung D (1976). Isolation and structure of an untriakontapeptide with opiate activity from camel pituitary glands. PNAS 73(4):11451148. PMID 1063395.

Morris AL, MacArthur MW, Hutchinson EG, Thornton JM (1992). Stereochemical quality of protein structure coordinates. Proteins 12:345. [PMID:1579569].

Morris GM, Goodsell DS, Halliday RS, Huey R, Hart WE, Belew RK, Olson AJ (1998). Automated Docking Using a Lamarckian Genetic Algorithm and an Empirical Binding Free Energy Function. J. Comput. Chem. 19:1639-1662.

Pogozheva ID, Przydzial MJ, Mosberg HI. 2005 Homology Modeling of Opioid Receptor-Ligand Complexes Using Experimental Constraints AAPS J. 07(02):E434-E448. DOI:10.1208/aapsj070243.

Wallace AC, Roman A Laskowski, Janet M Thornton (1995). LIGPLOT: A program to generate schematic diagrams of protein-ligand interactions. Protein Eng. 8(2):127-134. doi:10.1093/protein/8.2.127 http://www.pymol.org 